\title{
InNOVATIVE TEACHING MeTHOdS AND ENGINEERING EDUCATION RESEARCH
}

\author{
Angela van Barneveld and Johannes Strobel \\ Learning Design and Technology \\ Department of Curriculum and Instruction \\ Purdue University, West Lafayette, IN, USA \\ \{evanbarn@purdue.edu | jstrobel@purdue.edu\}
}

\begin{abstract}
Problem-based learning approaches have been deemed by research literature to be an optimal approach to develop engineering graduate competencies and attributes. While project-based capstone courses tend to be the norm, PBL has a lesser although highly recommended presence in the early years of an engineering program. With early year implementations of innovative pedagogies, engineering educators who persist in their PBL implementations encounter tensions at various levels and are required to devise strategies to manage the tensions.
\end{abstract}

This qualitative study focused on the variation in engineering educators' ways of experiencing tensions in PBL implementations, as well as how they managed the tensions $(n=14)$. In the specific context of the first two years of undergraduate engineering education, the research questions were (1) based on their teaching practices, what are the predominant tensions encountered by engineering educators? (2) What are the qualitatively different ways in which engineering educators experience tensions with a PBL implementation in their teaching practices? (3) How do engineering educators manage these tensions?

Results revealed tensions at both the classroom and system level. Examples of a classroom tension included the transitioning of students not only into engineering but also into PBL-oriented learning environments. System-level tensions included a misalignment in the perceived value assigned to teaching by the individual instructor and the organization.

For engineering educators considering the implementation of PBL, this study offered not only insights into potential tensions, but also the management strategies used to mitigate the tension. Implications for administrators, faculty development specialists, and curriculum designers are also discussed. 